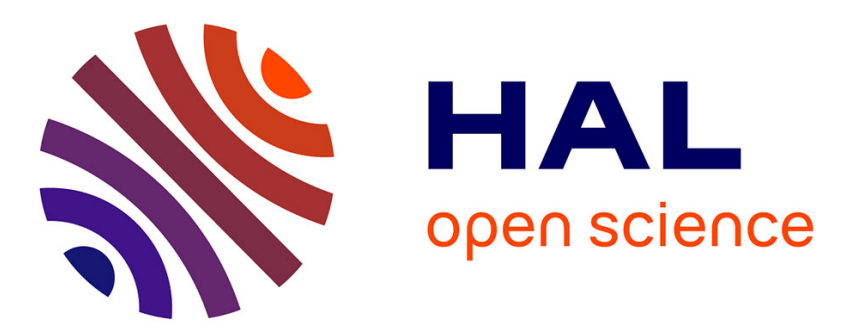

\title{
Development of a High Sensitivity Giant Magneto-Impedance Magnetometer: Comparison With a Commercial Flux-Gate
}

Basile Dufay, Sébastien Saez, Christophe Dolabdjian, Arthur Yelon, David Ménard

\section{To cite this version:}

Basile Dufay, Sébastien Saez, Christophe Dolabdjian, Arthur Yelon, David Ménard. Development of a High Sensitivity Giant Magneto-Impedance Magnetometer: Comparison With a Commercial Flux-Gate. IEEE Transactions on Magnetics, 2013, 49 (1), pp.85-88. 10.1109/TMAG.2012.2219579 . hal-00831475

\section{HAL Id: hal-00831475 \\ https://hal.science/hal-00831475}

Submitted on 7 Jun 2013

HAL is a multi-disciplinary open access archive for the deposit and dissemination of scientific research documents, whether they are published or not. The documents may come from teaching and research institutions in France or abroad, or from public or private research centers.
L'archive ouverte pluridisciplinaire HAL, est destinée au dépôt et à la diffusion de documents scientifiques de niveau recherche, publiés ou non, émanant des établissements d'enseignement et de recherche français ou étrangers, des laboratoires publics ou privés. 


\title{
Development of a high sensitivity Giant Magneto-Impedance magnetometer: comparison with a commercial Flux-Gate
}

\author{
B. Dufay* ${ }^{* \ddagger \S}$, S. Saez ${ }^{* \dagger \ddagger}$, C. Dolabdjian* ${ }^{* \dagger}$, A. Yelon ${ }^{\S}$, D. Ménard ${ }^{\S}$ \\ *Université de Caen Basse-Normandie, UMR 6072 GREYC, F-14032 Caen, France \\ ${ }^{\dagger}$ ENSICAEN, UMR 6072 GREYC, F-14032 Caen, France

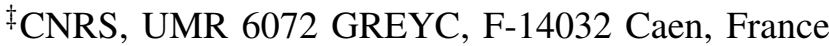

§École Polytechnique de Montréal, département de génie physique \& regroupement québécois des matériaux de pointe, Montréal, Québec, Canada H3C3A7

\begin{abstract}
Two versions of an operational giant magnetoimpedance (GMI)-based magnetometer, one of which is capable of working in an unshielded geomagnetic field, has been design, built and benchmarked against a commercial fluxgate magnetometer. The sensing element consists of a detection coil, strongly coupled to the GMI wire, in a two-port configuration. Its optimization is based on the surface impedance tensor of the sensing element, in which we include parasitic capacitance and geometric parameters of the coil. Conditions for optimizing the electronic noise level are deduced from the model recently published in IEEE Sensors Journal, 1317, 2011. The optimized sensor and its conditioning electronics are operated in a field-locked loop, using an external coil or the detection coil for feedback. Experimental noise performance correlates well with that expected from the sensitivity and noise models and are comparable to those of a commercial Flux-Gate magnetometer, offering a low-cost solution for high sensitivity magnetometry. However, the proposed GMI magnetometers still exhibit significant $1 / f$ noise.
\end{abstract}

\section{INTRODUCTION}

In spite of the great interest in the giant magnetoimpedance effect, mainly due to its potential for high sensitive and low cost magnetic sensing applications [1], only a small number of studies have been dedicated to their noise performance in real magnetometer configurations, ultimately determining the lowest measurable magnetic field. We have previously reported that the noise performance of GMI magnetometer is currently determined by the electronic conditioning noise rather than by the intrinsic noise of the GMI sensing element [2], [3], [4]. As a consequence, increasing the voltage sensitivity, in units of $\mathrm{V} / \mathrm{T}$, of the sensing element is required in order to reduce the electronic conditioning noise compared to that of the sensor. In this respect, GMI material optimization of the voltage sensitivity has been studied in ref. [5], whereas ref. [6] reports on the use of an optimal two-port network configuration, in which the GMI element is associated with a pick-up coil. This configuration is also equivalent to that referred to as off-diagonal GMI [7] or orthogonal flux-gate in the fundamental mode [8]. In a recent paper [9], based upon these investigations, we presented a fully optimized magnetometer, operating in a field-locked loop. Here, more attention is paid to the magnetometer performance. It is compared to that of widely used flux-gate magnetometers [10], [11], [12].

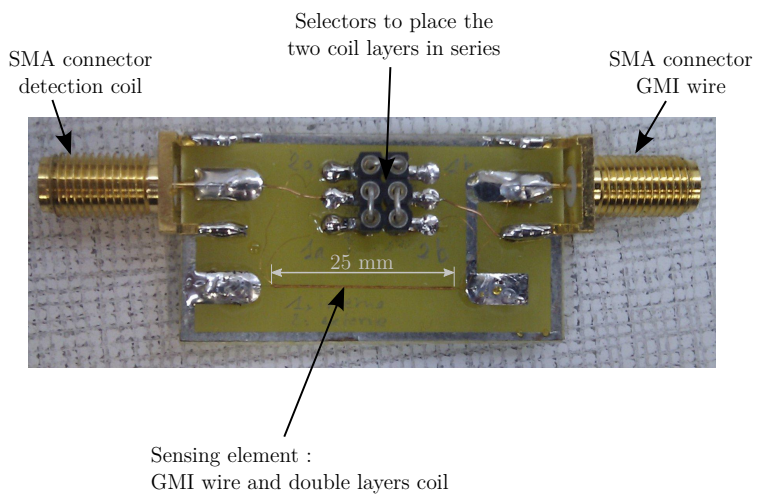

Figure 1. Photo of a sensing element, mounted on its sample holder.

The paper is organized as follows. Section II recalls the magnetometer design. We describe the GMI sensing element and its associated electronic conditioning. Section III presents the performance. A general conclusion is presented in section IV.

\section{Magnetometer DeSign}

\section{A. Off-diagonal GMI sensing element}

The sensing element consists of a thin pick-up coil directly wound on a $100 \mu \mathrm{m}$ diameter $\mathrm{CoFeSiB}$ amorphous ferromagnetic wire. This GMI wire was fully characterized in the study presented in ref. [5] (sample designation c3 with saturation magnetization $M_{s}=561 \mathrm{kA} / \mathrm{m}$, phenomenological Gilbert damping parameter $\alpha=0.020$ and electrical resistivity $\rho=$ $129 \mu \Omega . \mathrm{cm})$. The length of the whole sensing element is around $2.5 \mathrm{~cm}$. The number of turns in the coil is approximately $N=1000$, consisting of two layers in series. The picture of the sensing element, presented in Fig. 1, shows the details of the wound wire attached to the PCB support. Wire and coil are interfaced with the electronic circuit through SMA connectors. Jumpers are used to select the number of layers in series. 


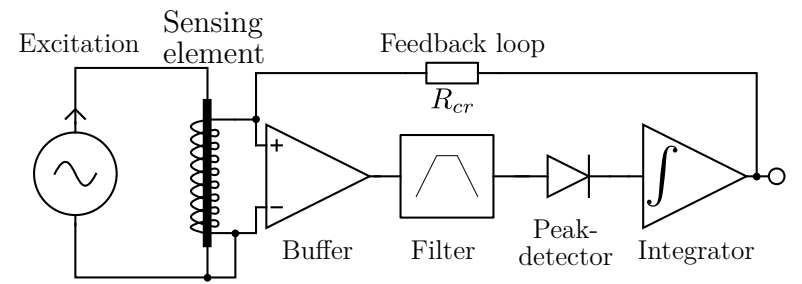

Figure 2. Block diagram of the conditioning electronic circuitry.

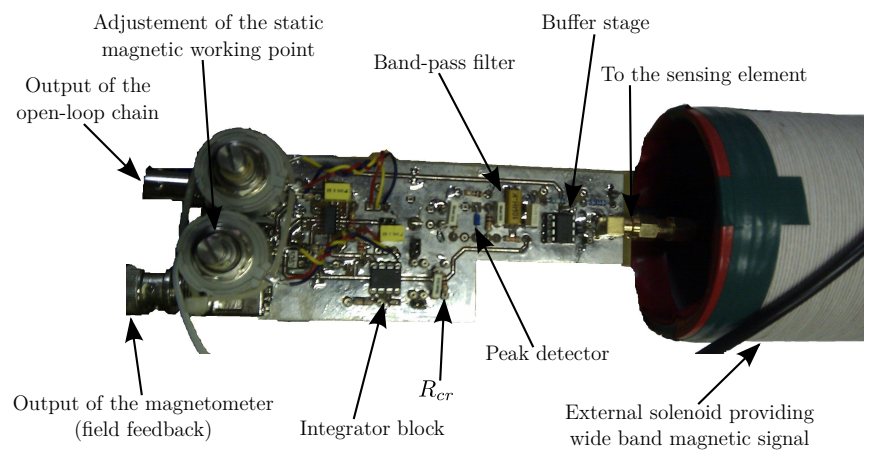

Figure 3. Picture of the electronic circuitry of the magnetometer.

\section{B. Electronic conditioning}

Figure 2 shows the diagram of electronic conditioning circuitry. In the first stage, the GMI wire is driven by a high frequency sine current. The generator is a sine voltage source converted to a current source by an injection resistor. The current amplitude is adjusted to the optimal value, determined by the physical properties of the GMI wire as discussed in ref. [5]. The excitation frequency, approximately $1 \mathrm{MHz}$, is adjusted to the resonance frequency of the sensing coil element, in order to maximize the sensitivity, as explained in refs. [9], [13]. A static bias current of $6 \mathrm{~mA}_{\mathrm{dc}}$ is also applied to the GMI wire to improve its noise figure [3].

The sensing element is followed by a voltage buffer providing a high input impedance for measurement of the voltage across the coil terminals. The next stage is a resonant bandpass filter, tuned to the excitation frequency, avoiding spurious harmonics to be demodulated at the detection stage. Finally, the carrier signal is demodulated at the detection stage, based on a peak detector as in ref. [3].

In order to extend the magnetic field range and deal with the non linear response of the GMI element, the latter is implemented in a field feedback loop configuration, providing a true, linear, magnetometer. The detection stage is thus followed by an integrator block, insuring that there is no static error in the output signal. The output voltage from the integrator block is fed back to a resistor, $R_{c r}$, in series with a coil, inducing a proportional magnetic field canceling the external field to be measured. In practice, we have used two kinds of feedback coil configuration. One is an external coil surrounding the entire sensing element, with no effect on the direct chain in any way. The other involves using the detection coil, as illustrated in Fig. 2. Although more compact, this latter arrangement introduces an impedance in parallel to

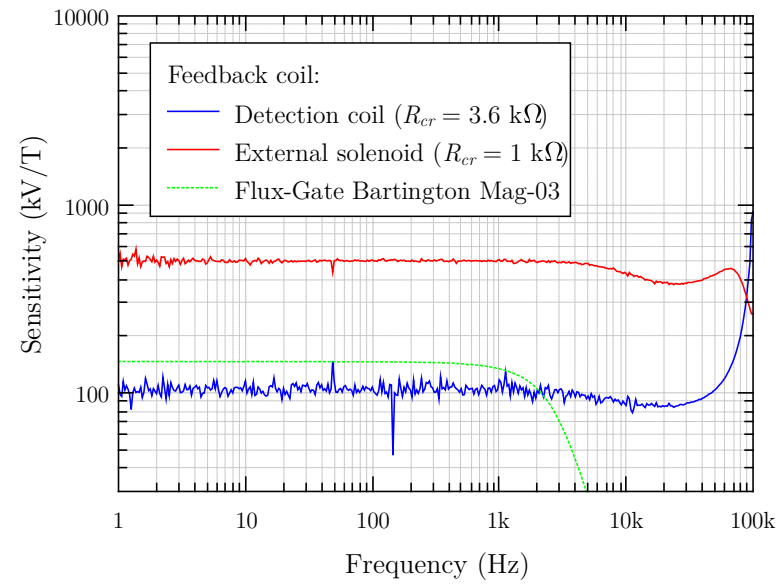

Figure 4. Transfer functions of the magnetometers for both type of feedback coil, compared to that of the commercial flux-gate Bartington MAG03. We note that the transfer functions were obtained from the response to a wide band excitation (PRBS). Measurement were done using a dynamic signal analyzer HP3562A configured in log-scale resolution and averaging ten consecutive acquisitions of $93 \mathrm{sec}$. each.

the detection coil which modifies the measurement chain, and influences its performance.

According to the choice of feedback configuration, the resistor $R_{c r}$ is adjusted to set the feedback gain. Assuming that direct gain is much higher than the inverse of feedback gain, it is this last which finally sets the sensitivity of the magnetometer. An offset adjustment on the output of this stage permits the setting of the static magnetic working point. A photo of the magnetometer prototype is presented in Fig. 3.

\section{Performance}

Magnetometers with both types of feedback configuration have been built and characterized. Their performances are presented here and benchmarked against those of a commercial flux-gate (Bartington MAG03).

For the case of the field feedback through an external coil, we used a $5 \mathrm{~cm}$ long solenoid, with a diameter of $4 \mathrm{~cm}$, surrounding the whole sensing element and its sample holder. The field-to-current ratio of the coil is approximately $2 \mathrm{mT} / \mathrm{A}$. In contrast, the magnetometer using the detection coil for feedback is more compact and has a field-to-current ratio of $36 \mathrm{mT} / \mathrm{A}$.

\section{A. Noise and band-pass}

Figure 4 shows the transfer functions of the two versions of the magnetometers along with that of the commercial fluxgate. For this measurement, the magnetometers were inserted in a wide band-pass solenoid fed by a white noise generator. Transfer functions were then given by the ratio between the spectral density of the white magnetic field noise applied to the magnetometer and the spectral density of its output.

For the external feedback configuration, $R_{c r}$ was adjusted to $1 \mathrm{k} \Omega$, leading to an expected sensitivity, given by the inverse of the feedback chain gain, of $500 \mathrm{kV} / \mathrm{T}$ in good agreement with the measured value of $490 \mathrm{kV} / \mathrm{T}$. The $-3 \mathrm{~dB}$ band-pass is around $90 \mathrm{kHz}$. 


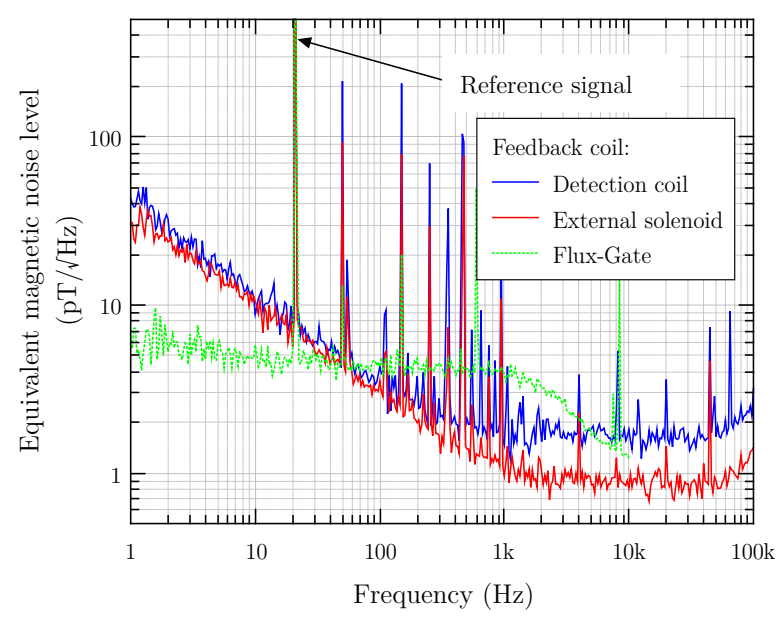

Figure 5. Equivalent magnetic noise spectral densities of the magnetometers for both types of feedback coil, compared to that of the commercial fluxgate Bartington MAG03. Spectral densities were measured using a dynamic signal analyzer HP3562A configured in log-scale resolution and averaging ten consecutive acquisitions of $93 \mathrm{sec}$. each.

In the other configuration, for which the feedback field is provided by the detection coil, the resistor $R_{c r}$ is adjusted to $3.6 \mathrm{k} \Omega$ leading to a measured sensitivity of $100 \mathrm{kV} / \mathrm{T}$. The $-3 \mathrm{~dB}$ band-pass is around $70 \mathrm{kHz}$, slightly lower than that with external feedback coil. The rise of the response around $70 \mathrm{kHz}$ is due to a resonance of the feedback loop. For comparison the sensitivity and band pass of the flux-gate are $143 \mathrm{kV} / \mathrm{T}$ and $3 \mathrm{kHz}$ respectively.

Figure 5 shows the equivalent magnetic noise levels of each configuration. The noise spectra were measured using a spectrum analyzer. The magnetometers were placed inside the GREYC magnetically shielded room (cf. Figure 6). This considerably reduce the noise from external magnetic fields. For noise measurements, the magnetometers were subjected to a magnetic reference signal of few $\mathrm{nT}_{\mathrm{rms}}$ at $20 \mathrm{~Hz}$ in order to control the sensitivity and thus the good operation of the measurement chain.

In the case of the external feedback coil, a noise level slightly below $1 \mathrm{pT} / \sqrt{\mathrm{Hz}}$ is measured in the white noise region. In the case of feedback through the detection coil, the white noise performance is somewhat degraded compared to that of the external feedback coil, reaching a level of $1.7 \mathrm{pT} / \sqrt{\mathrm{Hz}}$. This is due to the modification of the direct chain, introduced by the connection of the feedback loop to the sensor output, which degrades the input impedance of the buffer. Both configurations exhibit significant $1 / f$ noise at frequencies below $1 \mathrm{kHz}$. Cross correlation measurements suggest that this low frequency noise might originate in a magnetic noise intrinsic to the sensing element, but its cause is not yet fully determined.

\section{B. Full measurement scale and dynamic range}

The maximum amplitude of measurable magnetic field is limited by the maximum output voltage of the integrator and the feedback coil characteristic. For the external feedback coil, it is $\pm 20 \mu \mathrm{T}$, which is not sufficient to compensate the static

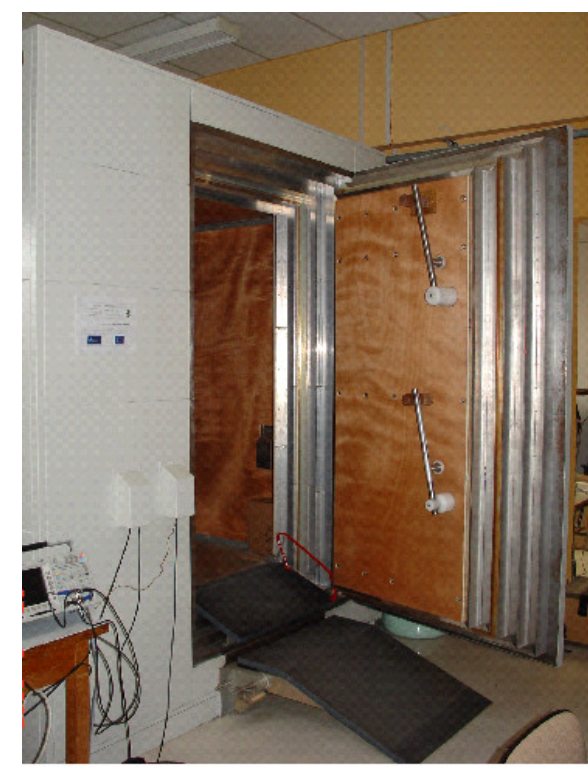

Figure 6. View of the GREYC laboratory magnetically shielded room (composed of six layers: 1 in soft iron, 4 in $\mu$-metal, 1 in aluminum).

component of geomagnetic field. Comparing this value to the equivalent magnetic noise level, it defines a dynamic range of $126 \mathrm{~dB} / \sqrt{\mathrm{Hz}}$ at $10 \mathrm{~Hz}$. Using the detection coil for feedback permits a higher full scale range thanks to the higher fieldto-current ratio of the feedback coil. The excursion is then $\pm 100 \mu \mathrm{T}$, allowing the use of this magnetometer in an open environment. Comparing this value to the equivalent magnetic noise level, it defines a dynamic range of $140 \mathrm{~dB} / \sqrt{\mathrm{Hz}}$ at $10 \mathrm{~Hz}$. In principle, the characteristic of the feedback coils could be adjusted, along with the other circuit parameters to obtain the appropriate field measurement range without degrading the noise performance.

\section{Slew-rate}

Slew-rate defines the maximum rate of magnetic field variations which the magnetometer is able to reproduce, and it is expressed in $\mathrm{T} / \mathrm{s}$. It is measured by recording the magnetometer output in response to a fast variation of magnetic field. Fig. 7 shows the corresponding measurement for the magnetometer with external feedback coil, for rising or falling field. The lowest value is measured for rising edge response and is around $117 \mathrm{mT} / \mathrm{s}$ and $450 \mathrm{mT} / \mathrm{s}$ for external feedback coil and detection coil, respectively.

\section{Comparison with flux-gate}

We have compared the practical optimized magnetometers with a widely used flux-gate magnetometer, as shown in Figs 4 and 5. Measured performances of each magnetometer are summarized in Table I which shows that the band-pass of GMI magnetometers is higher than that of the flux-gate. The equivalent magnetic noise level in white noise region is also favorable to the GMI magnetometer. The performance of the flux-gate magnetometer is superior in the low frequency region, due to the significant $1 / f$ noise of GMI magnetometers below $1 \mathrm{kHz}$. 
Table I

MAGNETOMETER PERFORMANCES.

\begin{tabular}{|c|c|c|c|c|c|c|c|c|}
\hline & Sensitivity & Band-pass & $\begin{array}{l}\text { Noise level } \\
\text { at } 1 \mathrm{~Hz}\end{array}$ & $\begin{array}{c}\text { Noise level } \\
\text { in white } \\
\text { noise } \\
\text { region }\end{array}$ & $\begin{array}{l}\text { Maximum } \\
\text { full scale }\end{array}$ & $\begin{array}{l}\text { Dynamic } \\
\text { range }\end{array}$ & Slew-rate & $\begin{array}{c}\text { Sensor } \\
\text { dimension }\end{array}$ \\
\hline & $\mathrm{kV} / \mathrm{T}$ & $\mathrm{Hz}$ & \multicolumn{2}{|c|}{$\mathrm{pT} / \sqrt{\mathrm{Hz}}$} & $\mu \mathrm{T}$ & $\mathrm{dB} / \mathrm{Hz}$ & $\mathrm{mT} / \mathrm{s}$ & $\begin{array}{c}l \times \varnothing \text { en } \\
\mathrm{mm}\end{array}$ \\
\hline \multirow{3}{*}{$\begin{array}{l}\text { External feedback coil } \\
\left(R_{c r}=1 \mathrm{k} \Omega\right) \\
\text { Re-use on the detection } \\
\text { coil }\left(R_{c r}=3,6 \mathrm{k} \Omega\right) \\
\text { flux-gate Bartington } \\
M A G-03 I E L 70 \text { (low } \\
\text { noise) }[14]^{b}\end{array}$} & 490 & $\begin{array}{c}\text { DC to } \\
90 \mathrm{kHz}\end{array}$ & 35 & 0,9 & \pm 20 & $126^{a}$ & 117 & $50 \times 40$ \\
\hline & 100 & $\begin{array}{l}\text { DC to } \\
70 \mathrm{kHz}\end{array}$ & 35 & 1,5 & \pm 100 & $140^{a}$ & 450 & $25 \times 3$ \\
\hline & 143 & $\begin{array}{l}\text { DC to } \\
3 \mathrm{kHz}\end{array}$ & $<6$ & $<6$ & \pm 70 & $141^{a}$ & - & $30 \times 8$ \\
\hline
\end{tabular}

${ }^{a}$ Compared to the noise level at $10 \mathrm{~Hz}$.

${ }^{b}$ This model is the one whose characteristics are presented in figs. 4 and 5. A newer model with greater dynamic range is now available.

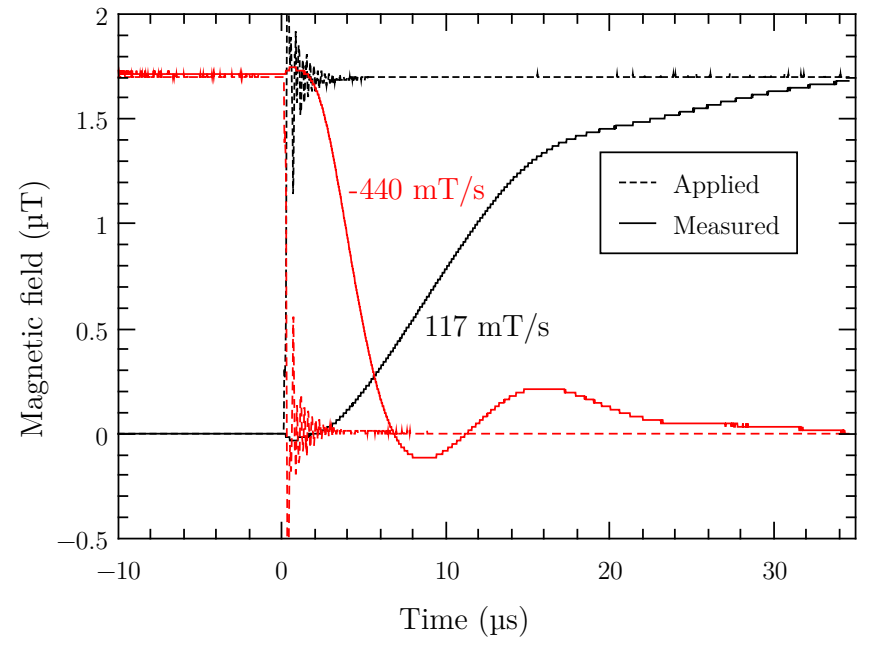

Figure 7. Slew-rate of the magnetometer with external feedback coil. Dashes correspond to the rising (black) or falling (red) edge of the applied magnetic field. Filled lines show the corresponding responses of the magnetometer. It appears that the slew-rate value depends upon the direction of the variation.

\section{CONCLUSION}

As we may see from Table I, the GMI magnetometers described here are quite competitive with flux-gate magnetometers, which fall in the same category in terms of performance and targeted applications. While the flux-gate magnetometer exhibits lower noise than the GMI magnetometers in the low frequency region (below $100 \mathrm{~Hz}$ ), the GMI magnetometers are superior at higher frequency in the white noise region. They also generally exhibit a higher band pass. For all other measured characteristics, such as sensitivity, full scale and dynamic range, all of the three have similar characteristics. Further investigations regarding other characteristics, such as very low frequency sensors stability, may be performed. In particular it would be of interest to investigate the behavior regarding perming effect of the ferromagnetic material [11] and the low frequency drift due to temperature fluctuations [15].

Since GMI is a less mature technology, we believe that there is more room for improvement in the future.

\section{ACKNOWLEDGEMENT}

The authors are indebted to Horia Chiriac who kindly provided samples for this study. This work was supported in part by the Natural Sciences and Engineering Research Council (NSERC) of Canada and by Custom Security Industries (CSI) Inc.

\section{REFERENCES}

[1] M. Knobel, M. Vázquez, and L. Kraus, "Giant magnetoimpedance," Handbook of Magnetic Materials, vol. 15, pp. 1-92, 2003.

[2] L. G. C. Melo, D. Ménard, A. Yelon, L. Ding, S. Saez, and C. Dolabdjian, "Optimization of the magnetic noise and sensitivity of giant magnetoimpedance sensors," Journal of Applied Physics, vol. 103, no. 3, p. $033903,2008$.

[3] L. Ding, S. Saez, and C. Dolabdjian, "Low Frequency Giant Magnetoimpedance Magnetometer Noise Versus Electronic Conditioning," Sensor Letters, vol. 5, no. 1, pp. 248-251, 2007.

[4] L. Ding, S. Nabily, S. Saez, J. Gieraltowski, and C. Dolabdjian, "Investigation of Giant Magnetoimpedance Magnetic Noise Comparison," Sensor Letters, vol. 5, no. 1, pp. 171-175, 2007.

[5] B. Dufay, S. Saez, C. Dolabdjian, A. Yelon, and D. Ménard, "Physical properties and giant magnetoimpedance sensitivity of rapidly solidified magnetic microwires," Journal of Magnetism and Magnetic Materials, vol. 324, no. 13, pp. 2091-2099, 2012.

[6] B. Dufay, S. Saez, C. Dolabdjian, A. Yelon, and D. Ménard, "Impact of electronic conditioning on the noise performance of a two-port network giant magnetoimpedance magnetometer," IEEE Sensors Journal, vol. 11, no. 6, pp. 1317-1324, 2011.

[7] S. Sandacci, D. Makhnovskiy, L. Panina, K. Mohri, and Y. Honkura, "Off-diagonal impedance in amorphous wires and its application to linear magnetic sensors," Magnetics, IEEE Transactions on, vol. 40, no. 6, pp. 3505-3511, 2004.

[8] E. Paperno, "Suppression of magnetic noise in the fundamental-mode orthogonal fluxgate," Sensors and Actuators A: Physical, vol. 116, no. 3, pp. 405-409, 2004.

[9] B. Dufay, S. Saez, C. Dolabdjian, A. Yelon, and D. Ménard, "Characterization of an optimized off-diagonal GMI-based magnetometer," IEEE Sensors Journal, 2012, accepted for publication (DOI: 10.1109/JSEN.2012.2216521).

[10] G. Musmann, Fluxgate Magnetometers for Space Research. Bod, 2010.

[11] P. Ripka, Magnetic sensors and magnetometers. Artech house, 2001, vol. 8.

[12] H. Hauser, L. Kraus, and P. Ripka, "Giant magnetoimpedance sensors," IEEE Instrumentation \& Measurement Magazine, vol. 4, pp. 28-32, 2001.

[13] S. Saez, B. Dufay, C. Dolabdjian, A. Yelon, and D. Ménard, "Effect of Parasitic Capacitance on GMI Magnetic Sensor Performance," Key Engineering Materials, 2012, under review.

[14] Mag-03, Three-axis magnetic field sensors, Bartington Intruments Ltd.

[15] M. Malátek, P. Ripka, and L. Kraus, "Temperature offset drift of gmi sensors," Sensors and Actuators A: Physical, vol. 147, no. 2, pp. 415418, 2008. 